\title{
Radiologic Assessment of Cervical Canal Stenosis Using Kang MRI Grading System: Do Clinical Symptoms Correlate with Imaging Findlings?
}

Hira Waheed ${ }^{1}$, Muhammad Salman Khan ${ }^{1}$, Aeman Muneeb ${ }^{2}$, Syed Jahanzeb ${ }^{3}$, Muhammad Nadeem Ahmad ${ }^{1}$

1. Radiology, Aga Khan University Hospital, Karachi, PAK 2. Internal Medicine, Lincoln Medical Center, New York, USA 3. Orthopedics, Civil Hospital Karachi, Dow University of Health Sciences, Karachi, PAK

$\square$ Corresponding author: Aeman Muneeb, aemanmuneeb@live.com

Disclosures can be found in Additional Information at the end of the article

\section{Abstract}

\section{Introduction}

Magnetic resonance imaging (MRI) is widely used in the evaluation of cervical canal stenosis and spinal cord compression. Kang et al. formulated a new MRI grading system for assessing canal stenosis which takes cord signal change into account. The purpose of the study was to determine the agreement between Kang's grading system and neurological symptoms.

\section{Methods}

A cross-sectional study was conducted at Aga Khan University Hospital between April 2014 and December 2015. Patients meeting inclusion criteria were enrolled. T2 sagittal and T2 axial MRI images were acquired and reported by a consultant neuroradiologist, in accordance with the MRI grading system suggested by Kang et al. Neurologic clinical symptoms were acquired by the history taken by the principal investigator. More than one neurologic symptoms and Kang MRI grade 2 or 3 were taken as positive evidence of cord compression resulting from canal stenosis.

\section{Results}

Amongst 126 subjects, $54 \%$ were females. Mean age of patients was $50.3 \pm 14.3$ years (range 1983 years). Average disease duration was $4.61 \pm 3.73$ (range 1-24 months). In the majority of the patients, the findings were found at the C5-C6 level. $65.1 \%$ of patients were identified positive for cervical canal stenosis by Kang grading system. Most common neurological symptoms were pain (99\%) and numbness (56\%). Cohen's Kappa was run to evaluate the agreement between

Received 05/31/2019 Review began 06/10/2019 Review ended 06/16/2019 Published 07/03/2019

\section{(c) Copyright 2019}

Waheed et al. This is an open access article distributed under the terms of the Creative Commons Attribution License CC-BY 3.0., which permits unrestricted use, distribution, and reproduction in any medium, provided the original author and source are credited. neurological symptoms and Kang grading system. There was a strong agreement between the two methods, $\mathrm{K}=0.81$ (95\% CI 0.70-0.92), $\mathrm{p}<0.001$.

\section{Conclusion}

There was a substantial agreement between Kang's grading system and the presence of clinical symptoms. The agreement was greatest in females, older patients, and those with longer duration of symptoms.

Categories: Neurology, Radiology, Neurosurgery

Keywords: cervical canal stenosis, spinal cord compression, magnetic resonance imaging

How to cite this article

Waheed H, Khan M, Muneeb A, et al. (July 03, 2019) Radiologic Assessment of Cervical Canal Stenosis Using Kang MRI Grading System: Do Clinical Symptoms Correlate with Imaging Findings?. Cureus 11(7): e5073. DOI 10.7759/cureus.5073 


\section{Introduction}

Cervical canal stenosis can result from a multitude of causes and can cause spinal cord compression leading to substantial morbidity. It requires prompt diagnosis and treatment to prevent long-term disabilities secondary to irreversible spinal cord injury [1]. Spinal cord compression affects the cervical cord in $10 \%$ cases and its prevalence is reported to be $24.4 \%$ [2]. Narrowing of the cervical canal can be caused by several conditions including tumors, infections, trauma, degenerative changes like intervertebral disc herniation, osteophytes, and ossification of posterior longitudinal ligaments [3-5].

The most common presenting symptom is pain; other symptoms include numbness, tingling, weakness, gait instability, bowel and bladder dysfunction, spasticity and paresthesia or rarely, permanent paraplegia [6]. Diagnosis is made with clinical history, neurological signs and radiological investigations including plain radiographs, computed tomography (CT) scans, myelography and magnetic resonance imaging (MRI). MRI is a more sensitive modality than CT scan and is the gold standard for imaging cervical cord [7]. MRI of the spine not only helps in diagnosing but also gives an idea of the possible treatment options [8].

It is important to assess the degree of canal stenosis for the better management of patients. A few studies have described various methods of assessment. Early studies performed by Pavlov et al. [9] and Torg et al. [10] were based on radiographs. Muhle et al. [11] graded cervical canal narrowing according to partial/complete obliteration of the anterior or posterior subarachnoid space, cervical cord compression or displacement. There are, however, a few limitations to this grading system as the definition of partial obliteration was unclear and no consideration was given to the signal change of cord. Signal change of the spinal cords is directly associated with the prognosis and Kang et al. formulated a new MRI grading system taking this parameter into account [3].

A universal criterion would ease the comparison of data from different investigations and would improve communication between clinicians and radiologists. With this purpose in mind, we conducted this study to determine the agreement between Kang's grading system and neurological symptoms.

\section{Materials And Methods}

This was a cross-sectional study conducted at the Department of Radiology at Aga Khan University Hospital, Karachi from April 2014 to December 2015 for a total duration of 20 months.

\section{Data sources and study population}

Sample Size Calculation

The sample size was calculated by sample size determination in health studies manual by the World Health Organization. By taking agreement between neurological symptoms and Kang's grading system as $80 \%$, the margin of error $7 \%$ and level of confidence $95 \%$, a sample size of 126 subjects was calculated. Through non-probability consecutive sampling, 126 patients were recruited in our study.

\section{Inclusion Criteria}

Adult patients of ages between 18 and 70 years and both sexes referred to the radiology department for MRI cervical spine examination for the evaluation of neurological symptoms. 


\section{Cureus}

\section{Exclusion Criteria}

Patients who have a history of acute trauma, infections, surgical history, tumors, lumbar spinal stenosis, combined brain infarction or any other intracranial lesion and the patients with symptoms at different cord level were excluded.

\section{Data Collection}

Patients meeting the inclusion criteria were enrolled in the study after taking informed consent. T2 sagittal and T2 axial images were taken through the cervical spine on Vantage Titan 3T. MRI reporting for cervical cord compression assessment was performed by a consultant neuroradiologist with five-year clinical experience. The radiologist assessed the presence and grade of cervical cord compression at the maximal narrowing point, in accordance with the MRI grading system suggested by Kang et al. Neurologic clinical symptoms were acquired by the history taken by the principal investigator.

\section{Outcome measures}

Based on clinical judgment, more than one neurologic symptom was considered positive evidence of canal stenosis and resulting cord compression. Kang's MRI grade 2 and above was considered positive evidence of cord compression since grade 0 and 1 stenosis do not involve the spinal cord; while grade 2 (spinal cord deformity) and grade 3 (spinal cord signal change) indicate that the spinal cord has been affected.

Cohen's Kappa statistic was calculated to measure the agreement between MRI grade and clinical symptoms. Statistical significance was set at alpha $=0.05$. All statistical analyses were performed using SPSS v. 22.0.

\section{Results}

Amongst 126 subjects, 54\% were females. Mean age of patients was $50.3 \pm 14.3$ years (range 1983 years). Average disease duration was $4.61 \pm 3.73$ (range $1-24$ months). In the majority of the patients (58/126 or 46.0\%), the findings were found at the C5-C6 level (Figure 1).

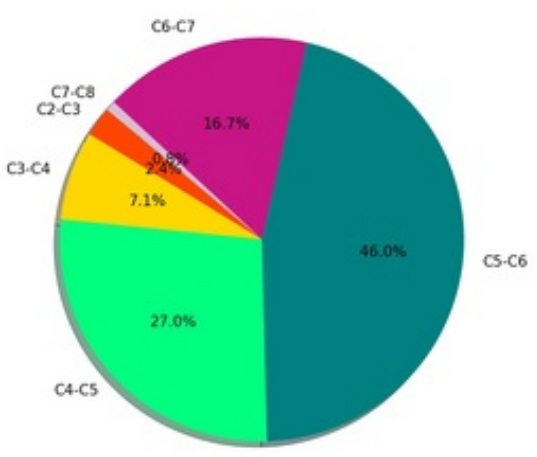

FIGURE 1: Level of cervical canal stenosis 


\section{Cureus}

Pain was the most common clinical symptom followed by numbness and tingling (Table 1)].

\begin{tabular}{|l|c|}
\hline Neurologic Symptoms & Frequency \\
\hline Pain & $125(99.2 \%)$ \\
\hline Numbness & $70(55.6 \%)$ \\
\hline Tingling & $32(25.4 \%)$ \\
Weakness & $5(4.0 \%)$ \\
Gait Instability & $6(4.8 \%)$
\end{tabular}

\section{TABLE 1: Frequency of neurologic symptoms.}

The association between Kang's grading and neurologic symptoms is noted in Table 2 . The majority of patients $(n=75,60 \%)$ with any neurologic symptoms had a positive result for cervical stenosis as measured by the Kang's grading system. In addition, kappa statistic revealed a strong agreement between the two methods ( $\mathrm{K}=0.81,95 \% \mathrm{CI}: 0.70-0.92, \mathrm{p}<0.001)$

\begin{tabular}{|c|c|c|c|c|c|}
\hline \multirow[t]{2}{*}{ KANG'S Grading } & \multicolumn{2}{|c|}{ Neurological Symptoms } & \multirow{2}{*}{ Kappa Test } & \multirow{2}{*}{$95 \% \mathrm{Cl}$} & \multirow{2}{*}{$p$-value } \\
\hline & Positive & Negative & & & \\
\hline Positive & 75 (59.5\%) & $7(5.6 \%)$ & \multirow{3}{*}{0.811} & \multirow{3}{*}{ 0.704-0.917 } & \multirow{3}{*}{$p<0.001$} \\
\hline Negative & $4(3.2 \%)$ & $40(31.7 \%)$ & & & \\
\hline Total & 79 (62.7\%) & 47 (37.3\%) & & & \\
\hline
\end{tabular}

TABLE 2: Agreement between Kang's grading system and neurological symptoms.

Of note, stratification by gender revealed stronger agreement between symptoms and MRI grading for females compared with males (female: Kappa 0.82; 95\% CI: 0.69-0.96 vs. male: Kappa 0.77; 95\% CI: 0.58-0.96) (Table 3). 


\section{Cureus}

\begin{tabular}{|c|c|c|c|c|c|}
\hline & \multicolumn{2}{|c|}{ Neurological Symptoms } & \multirow[t]{2}{*}{ Kappa Test } & \multirow[t]{2}{*}{$95 \% \mathrm{Cl}$} & \multirow[t]{2}{*}{$\mathrm{p}$-value } \\
\hline & Positive & Negative & & & \\
\hline \multicolumn{6}{|l|}{ MALE } \\
\hline Kang's Positive & $41(70.7 \%)$ & $4(6.9 \%)$ & \multirow{3}{*}{0.771} & \multirow{3}{*}{$0.582-0.960$} & \multirow{3}{*}{$p<0.001$} \\
\hline Kang's Negative & $1(1.7 \%)$ & $12(20.7 \%)$ & & & \\
\hline Total & $42(72.4 \%)$ & $16(27.6 \%)$ & & & \\
\hline \multicolumn{6}{|l|}{ FEMALE } \\
\hline Kang's Positive & $34(50 \%)$ & $3(4.4 \%)$ & \multirow{3}{*}{0.822} & \multirow{3}{*}{$0.686-0.958$} & \multirow{3}{*}{$p<0.001$} \\
\hline Kang's Negative & $3(4.4 \%)$ & $28(41.2 \%)$ & & & \\
\hline Total & 37 (54.4\%) & $31(45.6 \%)$ & & & \\
\hline
\end{tabular}

TABLE 3: Gender differences in agreement between Kang's grading system and neurological symptoms of spinal cord compression.

A sub-analysis stratified by disease duration demonstrated that patients who had been experiencing symptoms for a longer duration (> 5 months) had stronger agreement compared with patients who had been experiencing symptoms for lesser duration (> 5 months: Kappa 0.92; 95\% CI 0.76-1.00 vs. < 5 months: Kappa 0.78; 95\% CI 0.66-0.91) (Table 4). 


\section{Cureus}

Neurological Symptoms

Kappa Test

$95 \% \mathrm{Cl}$

p-value

Positive Negative

LESS THAN 5 MONTHS

Kang's Positive

Kang's Negative

Total

$55(56.7 \%)$

$7(7.2 \%)$

$3(3.1 \%)$

$32(33.0 \%)$

0.782

0.655-0.909

$p<0.001$

$58(59.8 \%) \quad 39(40.2 \%)$

MORE THAN 5 MONTHS

Kang's Positive

$20(69 \%)$

$0(0.0 \%)$

Kang's Negative

$1(3.4 \%)$

$8(27.6 \%)$

0.917

$0.757-1.000$

$p<0.001$

Total

$21(72.4 \%)$

$8(27.6 \%)$

TABLE 4: Disease duration differences in agreement between Kang's grading system and neurological symptoms of spinal cord compression.

Stratification by patient age group yielded a Kappa statistic of 0.73 (95\% CI 0.53-0.92) for patient age under 55 years and 0.87 (95\% CI 0.75-0.99) for patient age over 55 years (Table 5).

\begin{tabular}{|c|c|c|c|c|c|}
\hline & \multicolumn{2}{|c|}{ Neurological Symptoms } & \multirow[t]{2}{*}{ Kappa Test } & \multirow[t]{2}{*}{$95 \% \mathrm{Cl}$} & \multirow[t]{2}{*}{$p$-value } \\
\hline & Positive & Negative & & & \\
\hline \multicolumn{6}{|c|}{ LESS THAN 55 YEARS } \\
\hline Kang's Positive & $43(67.2 \%)$ & $4(6.3 \%)$ & \multirow{3}{*}{0.725} & \multirow{3}{*}{$0.534-0.915$} & \multirow{3}{*}{$p<0.001$} \\
\hline Kang's Negative & $3(4.7 \%)$ & $14(21.9 \%)$ & & & \\
\hline Iotal & $46((1.9 \%)$ & $18(28.1 \%)$ & & & \\
\hline \multicolumn{6}{|c|}{ MORE THAN 55 YEARS } \\
\hline Kang's Positive & $32(51.6 \%)$ & $3(4.8 \%)$ & \multirow{3}{*}{0.87} & \multirow{3}{*}{$0.747-0.993$} & \multirow{3}{*}{$p<0.001$} \\
\hline Kang's Negative & $1(1.6 \%)$ & $26(41.9 \%)$ & & & \\
\hline Total & $33(53.2 \%)$ & $29(46.8 \%)$ & & & \\
\hline
\end{tabular}

TABLE 5: Age differences in agreement between Kang's grading system and neurological symptoms of spinal cord compression. 


\section{Discussion}

Cervical canal stenosis can result from a number of causes and lead to cervical spinal cord compression, eventually leading to disability. In this context, multiple image-based grading systems help classify the extent of stenosis and involvement of the spinal cord. They are useful in communicating with clinicians about the extent of the stenosis. Combining radiological grade with clinical examination can build a full picture of the underlying pathology. Multiple systems have been proposed throughout the years, with Kang proposing a new MRI based system [3] that hopes to be more useful clinically. The purpose of our study was to evaluate the agreement and to assess whether this grading system correlates with neurologic symptoms for assessing spinal cord compression, that results from cervical cord stenosis. Among the 126 patients included in the analysis, the majority were middle-aged, females with a mean age of 50 years. Additionally, cervical cord stenosis was noted to occur most frequently at the C5-C6 spinal level. We found a strong agreement, $\mathrm{K}=0.81$ (95\% CI $0.70-0.92), \mathrm{p}<0.001$ between cervical stenosis causing cord compression (Kang's grade 2 and 3) and clinical symptoms. In addition, stratification analysis based on gender, disease duration, and age, all showed a strong and significant correlation.

Harrop et al. [12] studied cervical spinal cord compression and the presence of hyperintense signal within the cord on T2-weighted imaging. They evaluated the correlation between the radiological findings on MRI cervical spine and cord myelopathy and suggested a close correlation between those radiologic findings and cord myelopathy, but they did not grade the spinal cord compression. Takahashi et al. [13] reported the frequency of the high signal intensity of the cervical cord on T2-weighted imaging is directly proportional to the severity of clinical myelopathy and the degree of spinal canal compression. Similarly, Kang et al. reported a new MRI grading system for cervical canal stenosis. They classified cervical canal stenosis into the following grades based on T2- weighted sagittal images: grade 0 , absence of canal stenosis (subarachnoid space obliteration $\leqslant 50 \%$ ); grade 1 , subarachnoid space obliteration $>50 \%$; grade 2 , spinal cord deformity (compressed); and grade 3, spinal cord signal change. Kang et al. suggested that this new grading system provides a reliable assessment of cervical canal stenosis, with the interobserver agreement for the four grades ranging from 0.60 to 0.62 [3]. A similar study by Park et al. [1] reported that most of the patients with grade 0 cervical canal stenosis showed no neurologic manifestation, and patients with grades 2 and 3 cervical canal stenosis had positive neurologic manifestations. The clinical significance of grade 1 cervical canal stenosis was controversial. The agreement between MRI grade and clinical manifestations was high, similar to the findings in the present study.

Kang et al. [3] reported in their study that their grading system has a high interobserver agreement, determined by the intra-class correlation coefficient of 0.768 . Park et al. [1] reported an interobserver agreement of 0.925 which was also higher than reported in the study by Kang et al. [3]. Interestingly, our inter-observer agreement was higher than Kang et al. but lower than Park et al. probably due to experimental random error. However, since all studies report substantial reliability, the proposed grading system appears to be an accurate and reliable method for assessing the degree of canal stenosis. Park et al. [1] also reported that clinical correlation was higher in the older age group (over 50 years). Another similar study by Guen et al. [14] reported a new MRI grading system for lumbar canal stenosis. Guen et al. [14] suggested that this new grading system provides a reliable assessment, with the interobserver agreement for four grades ranging from 0.730 to 0.953 (intra-class correlation coefficient reliability). Highest agreement was found at the level of higher grading $(K=0.789)$, and the agreement for the older age group ( 55 years) was higher ( 0.870 vs 0.725$)$ than that for the younger age group ( 55 years). Female gender and longer duration of disease also had a better agreement. Similarly, our study also showed a better agreement for the older age group [Table 5], longer disease duration [Table 4] and female gender [Table 3]. 
The results of the study should be interpreted with certain limitations. One such limitation was that our study was based on recumbent MR images due to lack of availability of upright MRI. Studies have shown that conventional recumbent MRI of the cervical spine may underestimate disease because the imaging is performed in a nondynamic, non-weight bearing position.

\section{Conclusions}

In conclusion, Kang et al. grading system show considerable agreement with neurological symptoms of cervical canal stenosis and this agreement is higher in females, older age (>55 years) and those with a longer duration of disease (greater than 5 months). The current study provides useful information to patients, radiologists, and other physicians who may encounter cervical canal stenosis. As such, Kang's grading system can be utilized as a reference criterion to improve communication between clinicians and radiologists.

\section{Additional Information}

\section{Disclosures}

Human subjects: Consent was obtained by all participants in this study. College of Physicians and Surgeons Pakistan issued approval RAD-2012-175-1433. Animal subjects: All authors have confirmed that this study did not involve animal subjects or tissue. Conflicts of interest: In compliance with the ICMJE uniform disclosure form, all authors declare the following: Payment/services info: All authors have declared that no financial support was received from any organization for the submitted work. Financial relationships: All authors have declared that they have no financial relationships at present or within the previous three years with any organizations that might have an interest in the submitted work. Other relationships: All authors have declared that there are no other relationships or activities that could appear to have influenced the submitted work.

\section{References}

1. Park HJ, Kim SS, Chung EC, Lee SY, Park NH, Rho MH, Choi SH: Clinical correlation of a new practical MRI method for assessing cervical spinal canal compression. AJR Am J Roentgenol. 2012, 199:197-201. 10.2214/AJR.11.7599

2. Nagata K, Yoshimura N, Muraki S, et al.: Prevalence of cervical cord compression and its association with physical performance in a population-based cohort in Japan: the Wakayama Spine Study. Spine. 2012, 37:1892-1898. 10.1097/BRS.0b013e31825a2619

3. Kang Y, Lee JW, Koh YH, Hur S, Kim SJ, Chai JW, Kang HS: New MRI grading system for the cervical canal stenosis. AJR Am J Roentgenol. 2011, 197:134-140. 10.2214/AJR.10.5560

4. Cook C, Braga-Baiak A, Pietrobon R, Shah A, Neto AC, de Barros N: Observer agreement of spine stenosis on magnetic resonance imaging analysis of patients with cervical spine myelopathy. J Manipulative Physiol Ther. 2008, 31:271-276. 10.1016/j.jmpt.2008.03.006

5. Bernhardt M, Hynes RA, Blume HW, White 3rd AA: Cervical spondylotic myelopathy. J Bone Joint Surg Am. 1993, 75:119-128. 10.2106/00004623-199301000-00016

6. Yarbrough CK, Murphy RK, Ray WZ, Stewart TJ: The natural history and clinical presentation of cervical spondylotic myelopathy. Adv Orthop. 2012, 2012:480643. 10.1155/2012/480643

7. Bozzo A, Marcoux J, Radhakrishna M, Pelletier J, Goulet B: The role of magnetic resonance imaging in the management of acute spinal cord injury. J Neurotrauma. 2011, 28:1401-1411. 10.1089/neu.2009.1236

8. Hussain M, Nasir S, Murtaza G, Moeed U, Bari ME: Magnetic resonance imaging in cervical facet dislocation: a third world perspective. Asian Spine J. 2012, 6:29-33. 10.4184/asj.2012.6.1.29

9. Pavlov H, Torg IS, Robie B, Jahre C: Cervical spinal stenosis: determination with vertebral body ratio method. Radiology. 1987, 164:771-775. 10.1148/radiology.164.3.3615879

10. Torg IS, Pavlov HE, Genuario SE, Sennett B, Wisneski RJ, Robie BH, Jahre C: Cervical spinal stenosis with cord neurapraxia and transient quadriplegia. J Bone Joint Surg Am. 1986, 


\section{Cureus}

68:1354-1370.

11. Muhle C, Metzner J, Weinert D, et al.: Classification system based on kinematic MR imaging in cervical spondylitic myelopathy. AJNR Am J Neuroradiol. 1998, 19:1763-1771.

12. Harrop JS, Naroji S, Maltenfort M, et al.: Cervical myelopathy: a clinical and radiographic evaluation and correlation to cervical spondylotic myelopathy. Spine. 2010, 35:620-624. 10.1097/BRS.0b013e3181b723af

13. Takahashi MU, Yamashita YA, Sakamoto Y, Kojima RY: Chronic cervical cord compression: clinical significance of increased signal intensity on MR images. Radiology. 1989, 173:219-224. 10.1148/radiology.173.1.2781011

14. Guen YL, Joon WL, Hee SC, Kyoung-Jin O, Heung SK: A new grading system of lumbar central canal stenosis on MRI: an easy and reliable method. Skeletal Radiol. 2011, 40:1033-1039.

10.1007/s00256-011-1102-X 